\title{
Hypoglicemic and Antioxidant Activity of Petiveria alliacea in Diabetic Rat Models
}

\author{
Vania Azalia Gunawan ${ }^{1}$, Harlina Soetjipto², Arifa Mustika $^{3 *}$ \\ ${ }^{1}$ Faculty of Medicine Universitas Airlangga, Surabaya, Indonesia \\ ${ }^{2}$ Department of Physiology, Faculty of Medicine, Universitas Airlangga Surabaya, Indonesia \\ ${ }^{3}$ Department of Pharmacology, Faculty of Medicine, Universitas Airlangga Surabaya, Indonesia
}

\section{A R T I C L E I N F O}

\section{Article history:}

Received 13 May 2020

Received in revised form 29 May

2020

Accepted 03 May 2020

Available online 30 June 2020

\section{Keywords:}

Petiveria alliacea,

Blood glucose,

Malondialdehyde,

Streptozotocin (STZ),

Diabetes mellitus.

*) Corresponding author:

mustikaarifa@yahoo.com

\begin{abstract}
A B S T R A C T
Introduction: Diabetes mellitus is a degenerative disease characterized by chronic hyperglycemia conditions in the body. Various complications of diabetes mellitus are caused by oxidative stress condition. Petiveria alliacea (P. alliacea) is a potential plant and easy to grow in hot regions. Leaf extracts of $P$. alliacea contain flavonoids and tannins which work as antidiabetic and antioxidant. In addition, other compounds found in P. alliacea leaf extracts like linoleic acid and allantoin show an increase in insulin secretion. Therefore, this study aimed to determine the antidiabetic activity of ethanolic extract of $P$. alliacea.

Methods: We investigated the hypoglycemic and antioxidant effect of $P$. alliacea on STZ-induced diabetic rats. Rats were randomly divided into six groups named normal control, diabetes control, metformin $(150 \mathrm{mg} / \mathrm{kg} / \mathrm{d})$, low dose of P. alliacea $(90 \mathrm{mg} / \mathrm{kg} / \mathrm{d})$, intermediate dose $(180 \mathrm{mg} / \mathrm{kg} / \mathrm{d})$, and high dose $(360 \mathrm{mg} / \mathrm{kg} / \mathrm{d})$. Rats were orally given the treatment daily in the morning for fourteen days. At the end of the study, blood glucose level was measured and rats were sacrificed to measure blood malondialdehyde level.malondialdehyde

Results: P. alliacea extract dose of $90 \mathrm{mg} / \mathrm{kg}$ and $360 \mathrm{mg} / \mathrm{kg}$, and also metformin significantly decrease blood glucose levels. $P$. alliacea extract dose of $360 \mathrm{mg} / \mathrm{kg}$ was able to lower blood malondialdehyde level significantly which were not obtained on metformin.

Conclusion: This finding suggests that ethanolic extract of $P$. alliacea possess antidiabetic effect at least on rats.
\end{abstract}

\section{Introduction}

Diabetes mellitus (DM) is a degenerative disease that is experienced by most people in the world. According to $\mathrm{WHO}^{1}$, 347 million people worldwide suffer from diabetes mellitus and is expected in 2030, diabetes mellitus will be the seventh leading cause of death in the world. The deaths allegedly due to complications of diabetes affect various organs of the body. In Indonesia, the estimated prevalence will increase to 21.3 million in $2030 .^{2}$

$\mathrm{DM}$ is a condition of hyperglycemia in the body. DM can be caused due to the disruption of the synthesis and secretion of insulin, and also can be caused by the resistance of tissue sensitivity to insulin. Various complications of diabetes are caused by the imbalance condition of oxidants and antioxidants known as oxidative stress. Highly reactive free radicals can cause tissue damages. ${ }^{3}$ This leads to complications in many organs. Oxidative stress in the body can be determined by measuring the levels of malondialdehyde (MDA) in the blood which is the result of lipid peroxidation. MDA levels of blood increase along with oxidative stress in the body.

Petiveria alliacea is a plant often used to treat various diseases. This plant is very useful in the health fields, such as cancer, diabetes, muscular pain, skin diseases, various central nervous system disorders, respiratory and pulmonary infections, and malaria. ${ }^{4}$ In addition, $P$. alliacea also showed a protective effect against L. monocytogenes and immunomodulatory effect on hematopoiesis. ${ }^{5}$

The contents of $P$. alliacea leaf extract are flavonoids types astilbi, engeletin, and leridal-chalcone; flavanone types leridal, leridol, and leridol-5-methyl ether; flavonol types myricitrin; benzyl-2-hydroxyethylsulfide; isoarborinol; isoarborinol astetat; isoarborinol cinnamate; alkaloid types of allantoin; triterpene species ilexgenin; senfol, tannins, and polyphenols. ${ }^{6,7}$ $P$. alliacea leaves are also known to contain lipids such as lignoceryl lignocerate, linoleic acid, nonadecanoic acid, palmitic acid, stearic acid, as well as inorganic compounds such as $\mathrm{KNO}_{3}{ }^{7}$

Tannins in P. alliacea could provide a hypoglycemic effect. Linoleic acid and allantoin can stimulate insulin secretion. ${ }^{8,9}$ 
In addition, tannins and flavonoids also have antioxidant effects through capture free radicals, enhance the activity of endogenous antioxidants, and suppress oxidative stress. P. alliacea has an antioxidant capacity by $54 \% .{ }^{10}$ With its ability as an antioxidant, $P$. alliacea can suppress oxidative stress and reduce the complications of diabetes.

This study aims to determine the hypoglycemic and antioxidant activity of the ethanolic extract of $P$. alliacea in diabetic rats.

\section{Methods}

\section{Plant materials}

P. alliacea L. is an accepted Latin name, registered in The Plant List website. Leaves of $P$. alliacea were collected from Materia Medica, Batu, East Java, Indonesia. The identification made by Dr. Husin RM, Apt., M.Kes as chief of Materia Medica with certificate number 074/137/101.8/2015.

\section{Preparation of extract}

The extract used is the result of maceration using 96\% ethanol at the Laboratory of Pharmacology, Faculty of Medicine, Universitas Airlangga. Preparation of extract followed protocol implemented by Pharmacology Department of Universitas Airlangga. Dried powder of $P$. alliacea leaves (500 g) were soaked in 96\% aquaeus etanol within 3x24 hours (2 1, 1.5 1, $1.51)$ at room temperature. The leaves extract was filtered and concentrated by heating in a waterbath at temperature of $45^{\circ} \mathrm{C}$ in order to obtain a thick leaf extract of $P$. alliacea.

The extract was suspended in $1 \% \mathrm{CMC}-\mathrm{Na}$ at concentration of $9 \mathrm{mg} / \mathrm{ml}, 18 \mathrm{mg} / \mathrm{ml}$, and $36 \mathrm{mg} / \mathrm{ml}$. To make this, sequentially, $900 \mathrm{mg}, 1,800 \mathrm{mg}$, and 3,600 mg extracts were dissolved in $100 \mathrm{ml}$ of $1 \%$ CMC-Na. Different volume is given depends on the bodyweight of rats. The new suspension made every 6 days.

\section{Animals}

Experimental animals used were healthy males Wistar strain albino rats (Rattus norvegicus L.) aged 2-3 months with bodyweight \pm 200 grams. Rats were obtained from the Laboratory of Pharmacology, Faculty of Medicine, Universitas Airlangga. Selection of male sex aims to reduce hormonal influences. All animals were accustomed for approximately 1 week in clean cage with ad libitum water and food. The animals were treated in accordance with the standard guideline. The research work was approved by the Institutional Ethics Committee of Medical Research, Faculty of Medicine, Universitas Airlangga (174/EC/KEPK/FKUA/2015).

\section{Induction of experimental diabetes and experimental design}

Streptozotocin (STZ) used was purchased from Department of Physiology, Faculty of Medicine, Universitas Airlangga. Induction of diabetes followed induction protocol implemented by Purwanto and Liben.11. Rats were fasted for 4 hours and received single intraperitoneal injection of $50 \mathrm{mg} / \mathrm{kg} \mathrm{STZ}$ which was freshly dissolved in $0.01 \mathrm{~mol} / \mathrm{L}$ citrate buffer $(\mathrm{pH}$ 4.5). After injection, rats were given $10 \% \mathrm{w} / \mathrm{v}$ dextrose solution to prevent sudden hypoglycemic post-injection. Two days after injection, rats were fasted for 6 hours and blood glucose levels were measured. Rats with blood glucose levels $\geq 200 \mathrm{mg} / \mathrm{dl}$ were used.

On third day, rats were divided randomly into 6 groups of 6 rats each. The first group $(\mathrm{N})$ was normal rats treated with $1 \%$
CMC-Na. Negative control group (NC), also treated with 1\% $\mathrm{CMC}-\mathrm{Na}$ was used as negative control. Positive control group (PC) were given metformin at doses $150 \mathrm{mg} / \mathrm{kg}$. Metformin dose was determined based on Reagan-Shaw et al. Formula.12 Groups Pa190, Pal180, and Pal360, served as P.alliacea-treated groups and received extract at doses 90, 180, and $360 \mathrm{mg} / \mathrm{kg}$ respectively. Metformin and P.alliacea were dissolved in a $1 \%$ $\mathrm{CMC}-\mathrm{Na}$. Therapy was given intragastrically every morning for 14 days.

\section{Blood glucose level measurement}

After 14 days of treatments, rats were fasted for 6 hours and blood samples were taken from the lateral tail vein. Blood glucose level was measured using EasyTouch GCU (Bioptik Technology Inc.).

\section{Blood malondialdehyde (MDA) level measurement}

At the end of the study (day 15) levelof MDA was measured. The rats were sacrificed and blood was drawn from the heart. Measurement of MDA using Esterbauer and Cheeseman13 technique modified by the researcher and conducted at the Laboratory of Biochemistry, Faculty of Medicine, Universitas Airlangga. $500 \mu \mathrm{l}$ sample taken and added $4.5 \mathrm{ml}$ of cold PBS (phosphate buffered saline). $4 \mathrm{ml}$ of the supernatant is then taken and added to $1 \mathrm{ml}$ of $15 \% \mathrm{w} / \mathrm{v}$ Trichloroacetic acid (TCA). Furthermore, given $1 \mathrm{ml}$ of $0.37 \% \mathrm{w} / \mathrm{v}$ Thiobarbituric acid (TBA) solution in $0.25 \mathrm{~N} \mathrm{HCl}$ and heated in a waterbath at temperature $80^{\circ} \mathrm{C}$ for 15 minutes. Then cooled at room temperature for 60 minutes, and centrifuged at speed of 3,000 rpm for 15 minutes. Supernatant absorbance is then measured on a spectrophotometer at $\lambda=532 \mathrm{~nm}$.

\section{Statistical analysis}

All raw datas were analyzed using one-way ANOVA with Welch Test F continued with Games-Howell Post Hoc test, Paired t-test, and Wilcoxon Signed Rank test. Statistical analysis is using SPSS 17.0 statistical package for Windows. All values were displayed as mean $\pm \mathrm{SD}$. $\mathrm{P}$ values $<0.05$ were considered as significant.

\section{Results}

There was no difference in blood glucose level between groups before induction of diabetes. After 48 hours of injection, blood glucose level significantly increased and persisted until the end of the study (Figure 1).

As shown in table 1, blood glucose level was decreased in $P$. alliacea leaf extracts and metformin treated-groups. Unlike metformin, a significant reduction in MDA level was found in the group treated with $P$. alliacea at dose $360 \mathrm{mg} / \mathrm{kg}$ compared to negative control group $(\mathrm{p}=0.021)$.

\section{P. alliacea shows hypoglicemic activity with chronic treatment of diabetic rats}

After administration of $P$. alliacea leaf extracts for 14 days, blood glucose level was found to decrease significantly from $374.8 \mathrm{mg} / \mathrm{dl}$ to $222.5 \mathrm{mg} / \mathrm{dl}(90 \mathrm{mg} / \mathrm{kg})$ and $420 \mathrm{mg} / \mathrm{dl}$ to $209.2 \mathrm{mg} / \mathrm{dl}(360 \mathrm{mg} / \mathrm{kg})$. Metformin as an oral antidiabetic used in this experiment was also showed a significant reduction of blood glucose level (Figure 2). 
P. alliacea shows antioxidant activity with chronic treatment of diabetic rats

MDAlevel in the diabetic group $(7.048 \mathrm{nmol} / \mathrm{ml})$ was increased compared with non-diabetic $(6.747 \mathrm{nmol} / \mathrm{ml})$ although statistically not found a significant increase $(p=0.098)$. A significant reduction in MDA level was found in the group treated with P. alliacea at dose $360 \mathrm{mg} / \mathrm{kg}$ compared to negative control group $(\mathrm{p}=0.021)$. As shown in Figure 3 , the higher dose of the extract, the lower the blood level of MDA. This showed that higher antioxidant level was achieved while increasing the dose.

Table 1. Blood glucose level and blood MDA level of the experimental rats

\begin{tabular}{lcccc}
\hline \multicolumn{1}{c}{ Group } & \multicolumn{2}{c}{ Average of blood glucose level \pm SD (mg/dl) } & Average of blood MDA \\
& Pre-STZ & Pre-test & Post-test & level \pm SD (nmol/ml) \\
\hline Normal rats (N) & $114.6 \pm 13.3$ & $109.0 \pm 10.3$ & $107.4 \pm 9.4$ & $6.747 \pm 0.820$ \\
\hline Negative control (NC) & $118.4 \pm 13.0$ & $400.1 \pm 130.6$ & $309.0 \pm 147.3$ & $7.048 \pm 1.419$ \\
\hline Metformin treated-rats (PC) & $120.7 \pm 9.4$ & $427.0 \pm 66.4$ & $215.3 \pm 92.8$ & $4.751 \pm 0.756$ \\
\hline $90 \mathrm{mg} / \mathrm{kg}$ Pal-treated rats (Pal90) & $121.5 \pm 12.4$ & $374.8 \pm 63.4$ & $222.5 \pm 104.3$ & $6.312 \pm 4.486$ \\
\hline $180 \mathrm{mg} / \mathrm{kg}$ Pal-treated rats (Pal180) & $115.1 \pm 12.2$ & $401.3 \pm 64.4$ & $365.4 \pm 111.7$ & $4.040 \pm 2.457$ \\
\hline $360 \mathrm{mg} / \mathrm{kg}$ Pal-treated rats (Pal360) & $128.2 \pm 7.9$ & $420.0 \pm 47.5$ & $209.2 \pm 66.7$ & $2.101 \pm 0.423$ \\
\hline
\end{tabular}

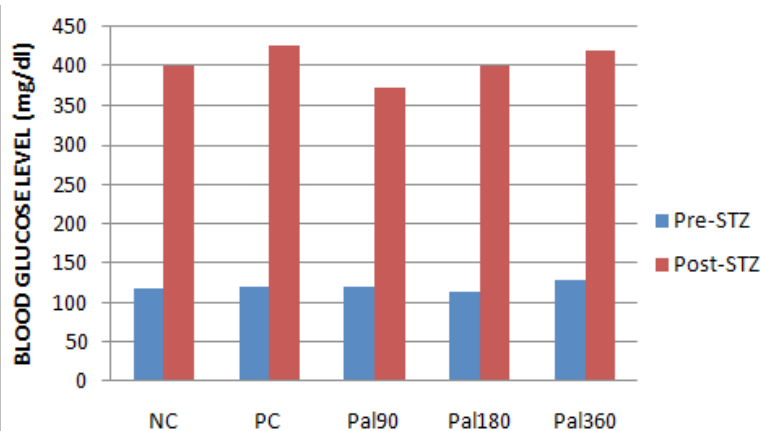

Figure 1 Comparison blood glucose level before and after STZ induction.

*NC: diabetic control rats

PC: metformin-treated diabetic rats

Pal90: diabetic rats treated with P.alliacea extract of $90 \mathrm{mg} / \mathrm{kg}$ Pal180: diabetic rats treated with P.alliacea extract of $180 \mathrm{mg} / \mathrm{kg}$ Pal360: diabetic rats treated with P.alliacea extract of $360 \mathrm{mg} / \mathrm{kg}$. Blood glucose level was measured after 6 hours fasting.

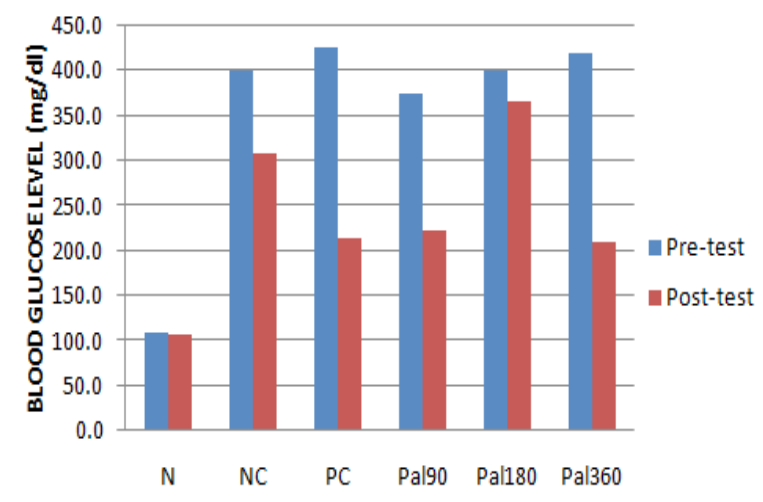

Figure 2. Effect of $P$. alliacea extract on pre-test and post-test blood glucose level of the experimental rats.

*N: normal rats

$\mathrm{NC}$ : diabetic control rats

PC: metformin-treated diabetic rats

Pa190: diabetic rats treated with P.alliacea extract of $90 \mathrm{mg} / \mathrm{kg}$ Pal180: diabetic rats treated with P.alliacea extract of $180 \mathrm{mg} / \mathrm{kg}$ Pal360: diabetic rats treated with P.alliacea extract of $360 \mathrm{mg} / \mathrm{kg}$. Blood glucose level was measured after 6 hours fasting

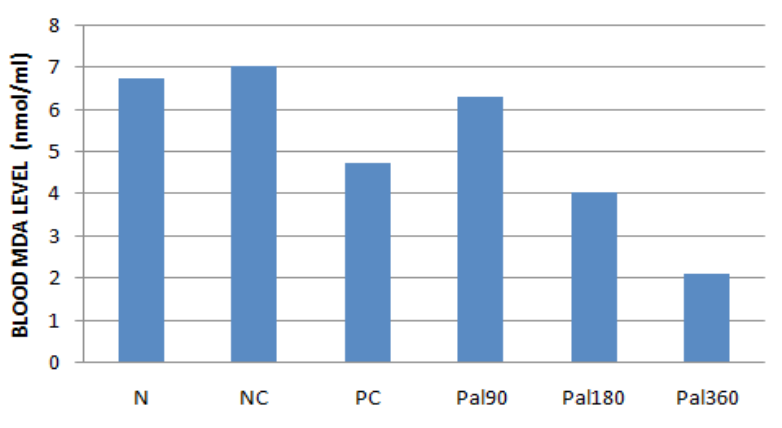

Figure 3. Effect of P. alliacea extract on blood MDA level of the experimental rats

*N: normal control rats

$\mathrm{NC}$ : diabetic control rats

PC: metformin-treated diabetic rats

Pa190: diabetic rats treated with P.alliacea extract of $90 \mathrm{mg} / \mathrm{kg}$

Pal180: diabetic rats treated with P.alliacea extract of $180 \mathrm{mg} / \mathrm{kg}$ Pal360: diabetic rats treated with P.alliacea extract of $360 \mathrm{mg} / \mathrm{kg}$. Blood glucose level was measured after 6 hours fasting.

\section{Discussion}

DM is a degenerative disease characterized by chronic hyperglycemia in the body affecting millions of people worldwide. The deaths allegedly due to complications of diabetes which affect various organs of the body. New treatment using plants with fewer side effects began to be utilized and studied for many years. In this study, antidiabetic effect of $P$. alliacea leaves in STZ-induced type 2 DM rats was studied. STZ has selective toxic effects on pancreatic $\beta$ cells that reach $90 \%$ success rate. ${ }^{11}$ STZ causes the death of pancreatic $\beta$-cells through a process of alkylation on the DNA and the formation of ROS that lead into DNA fragmentation. ${ }^{14,15}$ As a result, a significant increase in blood glucose level was obtained 48 hours post-injection (Figure 1).

When $P$. alliacea ethanolic leaves extract was administered for 14 days, it showed valuable hypoglycemic effect and significantly decreased blood glucose level almost same level as metformin-treated group especially at dose $90 \mathrm{mg} / \mathrm{kg}$ and $360 \mathrm{mg} / \mathrm{kg}$ (Figure 2). Lores and Cires (1990) found that extract from leaf and stem powder 
of $P$. alliacea was able to lower blood glucose level more than $60 \%$ after one-hour oral administration. ${ }^{16}$ This effect may due to $P$. alliacea containing flavonoids that increase the activity of endogenous antioxidant enzymes and regenerate damaged pancreatic $\beta$ cells. ${ }^{17}$ It has been found that antioxidants can improve insulin sensitivity. One of the oldest oral antidiabetic and commonly used as first line treatment in DM is metformin, which also works as insulin sensitizer. Few studies showed that metformin can decrease free radicals and restore antioxidant status which explained its protective role in preventing cardiovascular complications. ${ }^{18,19}$

Besides its antioxidant activity, $P$. alliacea leaves is thought to have a stimulating effect on insulin secretion. $P$. alliacea contain an unsaturated free fatty acids named linoleic acid which can stimulate insulin secretion and increase glucose-induced insulin secretion in rats in a dose-dependent manner. ${ }^{8}$ In addition, in a dose-dependent manner, allantoin compounds are also known can increase insulin secretion and decrease basal blood glucose level. ${ }^{9}$ Tannins have also been observed to increase insulin activity and enhance the glucose uptake through mediators of the insulin-signalling pathways, especially in adipocyte. These effects are proven by similarity of doseresponse curve of tannin-induced glucose transport with insulin. ${ }^{20,21,22}$ Phenolic compounds have been attributed in induction of $\beta$ cell regeneration and direct action in adipose tissue that enhance the insulin activity. ${ }^{22}$

Interestingly, as seen in Figure 2, it was found the doseresponse curves of $P$. alliacea was non-monotonic. Nonmonotonic dose-response (NMDR) may presents as a bellshaped or U-shaped profile with the highest responses at low and high dose as seen in our study. ${ }^{23}$ Several studies have described the effects of chemical compounds that can generate NMDR curves such as endocrine disruptor chemicals (EDC). ${ }^{24}$ These compounds affect the hormone system in the synthesis, secretion, transport, binding, and metabolism of hormones. These compounds can also mimic or block the effects of hormones and cause effect on sensitive tissues, including endocrine tissues, through several mode of actions. ${ }^{23,25}$ This finding may suggests that $P$. alliacea leaf extracts contain chemical compounds that can work as hormones or affect the endogenous hormone.

Hyperglycemic conditions trigger oxidative stress that can be measured by MDA level. Many experimental studies have shown the potential of plant derived antioxidant as treatment of DM. In this study, $P$. alliacea leaves extract decreased blood MDA levels. These results is in line with previous study showed $P$. alliacea had antioxidant effect by $54 \% .{ }^{10} \mathrm{P}$. alliacea leaves extract contains flavonoids and tannins that can work as an antioxidant and reduce oxidative stress condition. Flavonoids can work directly as an antioxidant which protect the body from free radicals and also increase the activity of antioxidant enzymes. ${ }^{17}$ Tannins are not only enhanced the activity of endogenous antioxidant, but also increased the antioxidant levels. Tannins also decreased the MDA concentrations in liver, heart, and kidney. ${ }^{26}$ Figure 3 shows that $P$. alliacea leaves extract decreased blood MDA levels and its relationship was dose-dependent. This means that the higher dose of the extract, the lower the blood level of MDA.

\section{Conclusion}

$P$. alliacea has a direct hypoglycemic effect and is thought to have a stimulating effect on insulin secretion and enhancing insulin activity. Moreover, $P$. alliacea can also work as an antioxidant. This antioxidant effect is not obtained on metformin.

\section{Conflict of Interest}

The author stated there is no conflict of interest

\section{References}

1. World Health Organisation. Diabetes. 2013 [cited 2014 May 31]. Available from: URL: http://www.who.int/mediacentre/factsheets/ fs $312 / \mathrm{en} /$

2. Wild S, Roglic G, Green A, Sicree R, King H. Global prevalence of diabetes. Diabetes Care.2004; 27:1047-1054.

3. Murray RK, Granner DK, Rodwell VW. Biokimia Harper 27th ed. Jakarta:EGC; 2009.

4. Randle MM, Riley CK, Williams LAD, Watson CT. A Systematic Review of the Traditional and Medicinal Uses of Petiveria alliacea L. In The Treatment of Chronic Diseases. J Plant Sci Res.2018; 5: 179.

5. Quadros MR, Brito ARMS, Queiroz ML. Petiveria alliacea L. extract protects mice against Listeria monocytogenes infection - effects on bone marrow progenitor cells. Immunopharmacology and Immunotoxicology. 1999;21:109-24.

6. Castellar A, Gagliardi R, Mansur E. In vitro propagation and establishment of callus and cell suspension cultures of Petiveria alliacea L., a valuable medicinal plant. J. Med. Plant. Res. 2011;5:1113-20

7. Raintree Nutrition. Presence of compounds in anamu (Petiveria alliacea).2013 [cited 2015 Oct 4]. Available from: URL: http://www. rain-tree.com/anamu-chemicals.pdf.

8. Lai MC, Teng TH, Yang C. The natural PPAR agonist linoleic acid stimulated insulin release in the rat pancreas. J Vet Med Sci. 2013;75:1449-54

9. Tsai CC, Chen LJ, Niu HS, Chung KM, Cheng JT, Lin KC. Allantoin activates imidazoline I-3 receptors to enhance insuline secretion in pancreatic $\beta$-cells. Nutrition \& Metabolism. 2014; 11:41.

10. Odukoya OA, Sofidiya MO, Samuel AT, Ajose I, Onalo M, Shuaib B. Documentation of wound healing plants in Lagos-Nigeria: inhibition of lipid peroxidation as in-vivo prognostic biomarkers of activity. Annals of Biological Research. 2012; 3:1683-89.

11. Purwanto B, Liben P. Model Hewan Coba untuk Penelitian Diabetes. Surabaya: PT Revka Petra Media; 2014.

12. Reagan-Shaw S, Nihal M, Ahmad N. Dose translation from animal to human studies revisited. FASEB Journal. 2007;22:659-61.

13. Esterbauer H, Cheeseman KH. Determination of aldehydic lipid peroxidation products: malonaldehyde and 4-hydroxynonenal. Methods in Enzymology.1990;186:407-21.

14. Elsner M, Guldbakke B, Tiedge M, Munday R, Lenzen S. Relative Importance of Transport and Alkylation for Pancreatic beta-cell Toxicity of Streptozotocin. Diabetologia. 2000;43:1528-33.

15. Szkudelski T. The mechanism of alloxan and streptozotocin action in B cells of the rat pancreas. Physiol Res. 2001;50:537-46.

16. Lores RI, Cires PM. Petiveria alleaceae L. (anamu) Study of the hypoglycemic effect. Medecine Interne. 1990;28:347-52.

17. Abdelmoaty MA, Ibrahim MA, Ahmed NS, Abdelaziz MA. Confirmatory studies on the antioxidant and antidiabetic effect of quercetin in rats. Indian J Clin Biochem. 2010;25:188-92.

18. Chakraborty A, Chowdhury S, Bhattacharyya M. Effect of metformin on oxidative stress, nitrosative stress and inflammatory biomarkers in type 2 diabetes patients. Diabetes Research and Clinical Practice. 2011;93(1):56-62.

19. Hou X, Song J, Li XN, Zhang L, Wang XL, Chen L, Shen YH. Metformin reduces intracellular reactive oxygen species levels by upregulating expression of the antioxidant thioreduxin via the AMPK-FOXO3 pathway. Biochemical and Biophysical Research Communications. 2010;396(2):199-205.

20. Anderson RA, Polansky MM. Tea enhances insulin activity. J. Agric. Food Chem. 2002;50: 7182-6.

21. Liu X, Kim JK, Li Y, Li J, Liu F, Chen X. Tannic acid stimulates glucose transport and inhibits adipocyte differentiation in 3T3-L1 cells. J Nutr. 2005;135:165-71.

22. Kumari M, Jain S. Tannins: an antinutrient with positive effect to 
manage diabetes. Res.J.Recent Sci. 2012; 1:1-8.

23. Lagarde F, Beausoleil C, Belcher SM, Belzunces LP, Emond C, Guerbet M, Rousselle C. Non-monotonic dose-response relationships and endocrine disruptors: a qualitative method of assessment. Environ Health. 2015; 14:13.

24. Vandenberg LN. Non-Monotonic Dose Responses in Studies of Endocrine

Disrupting Chemicals: Bisphenol A as a Case Study. Dose Response. 2014; 12:259-76.

25. Kavlock RJ, Daston GP, DeRosa C, Fenner-Crisp P, Gray LE, Kaattari S, Lucier G, Luster M, Mac MJ, Maczka C, Miller R, Moore J, Rolland R, Scott G, Sheehan DM, Sinks T, Tilson HA. Research needs for the risk assessment of health and environmental effects of endocrine disruptors: a report of the U.S. EPA-sponsored workshop. Environ Health Perspect. 1996; 104 : 715-40.

26. Velayutham R, Sankaradoss N, Ahamed KF. Protective effect of tannins from Ficus racemosa in hypercholesterolemia and diabetes induced vascular tissue damage in rats. Asian Pac J Trop Med. 2012; 5:367-73. 